\title{
Effect of Varying Levels of Acorn Flour on Antioxidant, Staling and Sensory Properties of Iranian Toast
}

\author{
Babak Mousavi ${ }^{\mathrm{a}}$, Sajad Ghaderi $^{\mathrm{b}}{ }^{*}$, Mohammad Ali Hesarinejad $^{\mathrm{c}}$, And Azizollah \\ Pourmahmoudi ${ }^{\mathrm{b}}$ \\ ${ }^{a}$ Department of Food Science and Technology, Faculty of Agriculture, Tarbiat Modarres University, P.O. Box \\ 14115-336 Tehran, Iran \\ b Department of Nutrition, Faculty of Health and Nutrition Sciences, Yasuj University of Medical Sciences \\ (YUMS), Iran \\ ${ }^{\mathrm{d}}$ Department of Food Processing, Research Institute of Food Science \& Technology (RIFST), P.O. Box \\ 91895-157-356, Mashhad, Iran \\ ${ }^{*}$ Corresponding author \\ Sajadghaderi1985@yahoo.com
}

Received: 3 September 2019; Published online: 18 October 2021

\begin{abstract}
Due to the high level of antioxidant activity of acorn fruits, they can be used as an ingredient the production of functional foods. The goal of the this research was to partially substitute wheat flour with varying levels $(10 \%-50 \% \mathrm{w} / \mathrm{w})$ of debittered acorn flour and to investigate its effects on the rheological characteristics of the dough, total phenolic content (TPC), staling, colour indices and sensory properties of toast bread. The farinograph degree of softening and water absorption of the dough decreased with increasing the acorn flour content, while the stability and time of development of the dough increased. Resistance and extensibility to deformation of the samples respectively increased and decreased compared to those of the control. Toast bread with $30 \%$ acorn flour replacement was observed to have lower staling than the control. The highest TPC (9.44 $\mathrm{mg} \mathrm{GAE} / \mathrm{g}$ ) and the lowest peroxide value $\left(0.36 \mathrm{~m}\right.$ eq $\left.\mathrm{O}_{2} / \mathrm{kg}\right)$ were obtained for the bread having $30 \%$ acorn flour substitution. Moreover, the breads showed darker crumbs with significantly lower specific loaf volumes. Overall, the bread with $30 \%$ of acorn flour substitution showed good rheological, staling properties and reasonable anti-oxidant content compared to the control bread as well as the highest sensorial acceptability.
\end{abstract}

Keywords: Acorn; Toast; Antioxidant; Staling

\section{Introduction}

Cereals operate an important duty in human nutrition all over the world. Because they include not only large amounts of energy sources, like starch, but also fatty acids, nutritive protein and dietary fibre. The positive effects on blood cholesterol and their dietary fibre content cause an increasing demand for nutritionally enriched breads with whole grains and different seeds (Mousavi \& Kadivar, 2018).

Copyright (C)2021 ISEKI-Food Association (IFA)
Acorns; the fruit of the oak tree; with approximately 500 species, has been mainly distributed in Europe, Asia and North America. Acorn has been used as the nut of the oak tree in various applications such as animals feeding, medicine as well as in the food industry, due to its antimicrobial, antioxidant and nutritional properties (Mohammadzadeh et al., 2013).

Acorn flour content of fat (of which over $80 \%$ is unsaturated), different sterols, considerable amounts of electrolytes (phosphorus, zinc, cop- 
per, iron, magnesium and calcium) and proteins, is acceptable from a nutritional point of view (Ghaderi-Ghahfarrokhi et al., 2017). Acorn meal could be a functional nutritional ingredient in foods that include wheat flour such as pastries, noodles, muffins, cookies, breads and desserts with a growing presence in the food industry, to improve the eating habits of personal clients and the general population for well-being benefits and disease prevention (Polimac \& Komlenić, 2016). Moreover, acorns contain phenolic compounds like the derivatives of proanthocyanidins, benzoic acid, flavons, chalkons, cinnamic acid, quinones, and amino phenolic compounds with high antioxidant activity, which can break the chain of radical reactions, bind with metals and scavenge free radicals. Increasing the consumption of these compounds leads to a decrease in the risk of digestive diseases and dangerous cancers (Ferrari \& Torres, 2003). Dietary supplements, nutraceuticals, organic foods and functional foods as the worldwide nutritional health products (NHPs) have become popular in an extremely fast growing market. In addition to biologically nutritious components acorns possess biologically active substances that enable the utilization of acorns in the preparation of functional foods (Rakić et al., 2004). In spite of the extensive utilization of acorn flour in bakery products, no study has been carried out to consider the effects of the partial replacement of wheat with the acorn flour in Iranian toast production. The aims of this research were (I) to study the rheological characteristics of the dough such as water absorption, development times and stability, resistance to extension and extensibility and (II) to evaluate the total phenolic content, colour indices, staling, peroxide value and sensory properties of the toast breads.

\section{Materials and Methods}

\section{$2.1 \quad$ Materials}

Acorn Flour (moisture content: $4.2 \pm 0.1 \%$ dry basis (db); $150 \mu \mathrm{m}$ mean particle size) was provided from a local market in Yasouj city (Kohgiluyeh and Boyer-Ahmad Province, Iran). The wheat samples (Sepahan (HRW)) was obtained from field trials grown at Tarbiat Modares University Agricultural Research Centre, in 2018. Wheat samples were milled in a laboratory mill supplied with different breaks, reduction rollers and sifters. Toast bread improver and yeast were obtained from Kobodena Co., Yasouj, Iran. All other chemicals and reagents used were at least of analytical grade and provided form Sigma Aldrich (St. Louis, MO, USA).

\subsection{Chemical tests}

The physicochemical properties of wheat and acorn flours, including moisture, protein, ash, fat, total phenolic contents and crude fibre were analysed according to AACC (2000) methods No. 46-12, 33-17 , 30-10, 44-16 and 08-01 respectively. Energy values were determined according to the general Atwater factor according to Atwater (1902). Energy $(\mathrm{kcal})=9 \times(\mathrm{g}$ fat $)+4$ $\times(\mathrm{g}$ protein $)+3.75 \times(\mathrm{g}$ carbohydrate $)$. The results were expressed as $\mathrm{g}$ per $100 \mathrm{~g}$ of dried mass.

\subsection{Farinograph and extensograph tests}

The attributes of the dough during mixing were determined using a farinograph (Brabender, Duisburg, Germany) according to AACC. No. 54-21 (2000) method. The softening degree, dough development time, water absorption and stability time of the control and three acornadded samples were obtained. Extensibility and resistance to extension measurements were carried out in accordance with the standard procedure utilizing an extensograph-E (Brabender, Duisburg, Germany). The dough developed utilizing the farinograph-E was split into two 150 -g loaves and retained for 45-135 min for proving. The resistance to extension and dough extensibility were obtained so. All evaluations were performed in duplicate at $25{ }^{\circ} \mathrm{C}$.

\subsection{Dough preparation}

According to AACC (2000) method, the amount of water measured by the farinograph was added 
to the dry ingredients then mixed until homogeneous dough was achieved corresponding to the recipe of Iranian toast. The control contain $(100 \%$ wheat flour) and five acorn/wheat $(0,10,20,30$, 40 and $50 \%$ acorn flour substituting for wheat flour) dough samples were prepared and utilized in the extensographic measurements to analyse the rheological characteristics of the dough.

\subsection{Toast bread making procedure}

Wheat flour was mixed with compressed yeast and salt, each comprising $1.5 \mathrm{~g} / 100 \mathrm{~g}$ of the total mixture and previously dissolved in water. The amount of water added to each formulation varied according to the farinographic water absorption index, previously determined (Table 1). For each formulation, the ingredients such as toast improver including alpha amylase, glycerol mono-stearate (GMS), ascorbic acid, ammonium chlorate, corn oil, salt, sugar and yeast were mixed in an automatic spiral mixer (Bomann, Clatronic s.r.l., Italy), for $12 \mathrm{~min}$. Instantly after mixing, the dough was left to rest for $15 \mathrm{~min}$ at room temperature. After that, the dough was divided into portions $300 \mathrm{~g}$, moulded into cylinder shapes, put in baking pans $(8 \times 15 \times 5 \mathrm{~cm})$ and left to rest for $45 \mathrm{~min}$ in a proofing cabin at $30{ }^{\circ} \mathrm{C}$ and $80 \% \mathrm{RH}$. Samples were baked for 35 min at $205^{\circ} \mathrm{C}$ in an oven (Self Cooking Center ${ }^{\circledR}$, Rational International AG), with vapor injection in the first instants of baking. Two hours after removing the samples from the oven they were packaged in perforated OPP film and stored at room temperature $\left(20{ }^{\circ} \mathrm{C}, 60 \% \mathrm{RH}\right)$ for further analysis. For each sample, two baking experimental tests were performed and four loaves were obtained from each baking test.

\subsection{Differential Scanning Calorimetry}

The differential scanning calorimetry (DSC) evaluations were performed using a Perkin-Elmer Model DSC 6 (Connecticut, USA). DSC curves determine the thermal properties of starch retrogradation in the toast bread. In this measurement an indium standard was utilized as calibrator calorimeter. Enthalpy $(\Delta \mathrm{H} \mathrm{J} / \mathrm{g})$ was ob- tained for each endotherm at $22{ }^{\circ} \mathrm{C}$ for 3 days (24, 48 and $72 \mathrm{~h}$ after baking). The analyses were carried out in triplicate (Primo-Martin et al., 2007).

\subsection{Total phenolic content}

\section{Extraction and determination of polyphenols}

Concentrated hydrochloric acid: methanol: water $(1: 80: 10, \mathrm{v} / \mathrm{v})$ mixture at room temperature for $5 \mathrm{~h}$ extracted soluble phenolics from bread samples. Insoluble phenolics' extraction was performed with methanol and concentrated sulphuric acid $(10: 1, \mathrm{v} / \mathrm{v})$ for $20 \mathrm{~h}$ at $85^{\circ} \mathrm{C}$ according to the method previously described by Hartzfeld et al. (2002). Total phenolic content (TPC) was calculated as the total of the soluble and hydrolysable polyphenolic fractions as mentioned by Perez-Jimenez and Saura-Calixto (2005). TPC was obtained according to the Folin-Ciocalteau procedure as represented by Singleton (Singleton et al., 1999). Data were evaluated as average values $(\mathrm{n}=3)$ and showed as $\mathrm{mg}$ of Gallic acid equivalent (GAE)/ g of dry matter (DM) and analyses were conducted in triplicate.

\section{Determination of peroxide value}

The evaluation of the peroxide value $(\mathrm{PV})$ was performed according to the AOCS (2003) procedure. Accordingly, $2 \mathrm{~g}$ oil, extracted from bread according to the AOCS method 3-54, were weighed in a glass Erlenmeyer flask and mixed with $10 \mathrm{ml}$ chloroform. Glacial acetic acid (15 $\mathrm{ml}$ ) and a saturated aqueous solution of potassium iodine $(1 \mathrm{ml})$ were added and then shaken and stored in the dark for 5 min. Distilled water $(75 \mathrm{ml})$ was then added and mixed and the free iodine was determined with a $0.01 \mathrm{~N}$ solution of sodium thiosulphate, using a starch solution $(10 \mathrm{~g} / \mathrm{l})$ as indicator. All analyses were carried out in triplicate. 
Biotechnological properties of Acorn toast | 325

Table 1: Effect of substituting acorn flour on mixing properties of wheat flour dough with $70 \%$ extraction

\begin{tabular}{|c|c|c|c|c|c|c|c|c|c|c|}
\hline \multirow{4}{*}{$\begin{array}{c}\text { Acorn flour } \\
\text { level }(\%)\end{array}$} & \multirow{2}{*}{\multicolumn{4}{|c|}{ Farinograph properties }} & \multicolumn{6}{|c|}{ Extensograph properties } \\
\hline & & & & & \multicolumn{6}{|c|}{ Proving time } \\
\hline & & & & & \multicolumn{2}{|c|}{$45(\min )$} & \multicolumn{2}{|c|}{$90(\min )$} & \multicolumn{2}{|c|}{$135(\min )$} \\
\hline & WA $(\%)$ & $\operatorname{DST}(\min )$ & $\mathrm{DDT}(\min )$ & $\mathrm{DS}(\mathrm{BU})$ & $\mathrm{RE}(\mathrm{N})$ & $\mathrm{EX}(\mathrm{mm})$ & $\mathrm{RE}(\mathrm{N})$ & $\mathrm{EX}(\mathrm{mm})$ & $\mathrm{RE}(\mathrm{N})$ & $\mathrm{EX}(\mathrm{mm})$ \\
\hline 0 & $60.2 \pm 3.3^{a}$ & $1.9 \pm 0.06^{c}$ & $1.1 \pm 0.044^{c}$ & $190 \pm 5.6^{a}$ & $112.4 \pm 2.5^{e}$ & $201 \pm 5.5^{a}$ & $104.3 \pm 3.1^{d}$ & $174 \pm 1.1^{a}$ & $87.6 \pm 2.4^{d}$ & $133 \pm 2.1^{a}$ \\
\hline 10 & $58.4 \pm 2.12^{a b}$ & $2.0 \pm 0.55^{c}$ & $1.3 \pm 0.02^{b}$ & $100 \pm 4.7^{b}$ & $170.9 \pm 3.6^{d}$ & $186 \pm 3.43^{b}$ & $167.5 \pm 2.5^{c}$ & $163 \pm 2.3^{a}$ & $141.4 \pm 2.03^{c}$ & $121 \pm 5.6^{b}$ \\
\hline 20 & $57.1 \pm 3.14^{a b}$ & $2.3 \pm 0.39^{c}$ & $1.3 \pm 0.071^{b}$ & $92 \pm 3.2^{b}$ & $207.4 \pm 4.52^{c}$ & $144 \pm 2.6^{c}$ & $256.4 \pm 3.8^{a}$ & $125 \pm 2.05^{b}$ & $211.5 \pm 4.8^{a}$ & $98 \pm 4.8^{c}$ \\
\hline 30 & $54.3 \pm 1.06^{b}$ & $3.0 \pm 0.11^{b}$ & $1.4 \pm 0.05^{b}$ & $90 \pm 3.29^{b}$ & $325.4 \pm 2.88^{a}$ & $112 \pm 4.5^{d}$ & $268.6 \pm 5.4^{a}$ & $110 \pm 1.19^{b c}$ & $198.3 \pm 6.2^{b}$ & $96 \pm 1.5^{c}$ \\
\hline 40 & $44.8 \pm 3.31^{c}$ & $3.6 \pm 0.25^{b}$ & $1.8 \pm 0.11^{b}$ & $20 \pm 1.25^{c}$ & $277.1 \pm 7.62^{b}$ & $92 \pm 5.1^{e}$ & $212.3 \pm 4.6^{b}$ & $91 \pm 2.3^{c}$ & $209.8 \pm 5.5^{a}$ & $80 \pm 3.4^{d}$ \\
\hline 50 & $37.9 \pm 2.56^{d}$ & $4.8 \pm 0.35^{a}$ & $2.3 \pm 0.15^{a}$ & $16 \pm 0.9^{c}$ & $211.8 \pm 5.12^{c}$ & $85 \pm 4.7^{e}$ & $215.1 \pm 5.1^{b}$ & $85 \pm 2.15^{c}$ & $201.1 \pm 4.3^{a b}$ & $82 \pm 2.12^{d}$ \\
\hline
\end{tabular}

WA, water absorption ; DDT, dough development time; DST, dough stability time; DS, degree of softening; RE, Resistance to extension ; EX, extensibility; $\mathrm{BU}$ (Brabender unit). Values are expressed as mean of two replications \pm S.D. Different letters show significant differences at a significance level of $5 \%$.

\subsection{Bread physical properties}

The volume of bread was measured in duplicate utilizing a volume analyser BVM-L370 TexVol Instruments (Viken, Sweden). Crumb bread colour was determined in the CIE $L^{*} a^{*} b^{*}$ system through the reflectance procedure using Color i5 spectrophotometers (X-Rite, USA) adjusted for the following parameters: illuminate D65, measuring geometry d/8, slit width $25 \mathrm{~mm}$, observer $10^{\circ}$ (Marpalle et al., 2014). The colour of all samples was determined $1 \mathrm{~h}$ after baking. A mean of four evaluations for $\mathrm{L}^{*}, \mathrm{a}^{*}$ and $\mathrm{b}^{*}$ values were saved. Average values of at least 2 breads were taken for statistical goals. Firmness of bread crumb was evaluated by a puncture test utilizing an Instron 4301 (Instron LTD. High Wycombe, UK). On the test day, crosshead speed was set at $10 \mathrm{~cm} / \mathrm{min}$ and bread samples were punctured with a $3-\mathrm{mm}$ cylindrical probe. The result of the puncture tests were achieved from force-distance curves and the firmness parameter was taken as the force $(\mathrm{N})$ required to puncture the bread crumb. All analyses were carried out in triplicate.

\subsection{Sensory evaluation}

The sensory acceptability was performed on the bread samples with the various percentages of acorn flour. Each bread slice ( $2 \mathrm{~cm}$ thick) coded with a number and served to each the panel, consisted of 24 untrained assessors (aged between 21 and 43 years) who evaluated the bread overall acceptability, under normal (daylight) illumination. The measuring of acceptability of the acorn toast bread samples was taken by a nine-point hedonic rating scale, utilized with scores of 1,5 and 9 representing "dislike extremely", "neither like not dislike" and "like extremely" respectively (Lin et al., 2009).

\subsection{Statistical analysis}

Statistical software of SAS v. 9 was utilized for the statistical analysis of the data achieved in this research. All data were subjected to analysis of variance (ANOVA) and the means of the results at a significance level of $5 \%$ were compared by Duncan's multiple range test.

\section{Results and Discussion}

\subsection{Chemical analysis of flour types}

Compositions of acorn flour (AF) and wheat flour (WF) are presented in Table 2. One of the important factors influencing the overall quality of flours (colour, flavour, texture) is $\mathrm{pH}$, according to Sabrin (2009). The moisture content of flours is a critical quality factor for transportation, packaging and preservation. Moreover, the moisture content also should be standard. The results illustrated that the $\mathrm{pH}$ values of $\mathrm{AF}$ and $\mathrm{WF}$ were the same (5.64). AF had a lower moisture $(4.12 \%)$ and protein $(4.21 \%)$ contents than

IJFS | October 2021 | Volume $10 \mid$ pages 322-333 
WF but higher fat (6.49\%), fibre $(3.11 \%)$ and ash $(2.19 \%)$ contents. Hadnadev et al. (2011) reported that the fat content of wheat flours was within the range of $0.75-2.34 \%$. Sabrin (2009) introduced acorn is a remarkable food source of calorie because of its high levels of fat. The Amount of fat can affect staling, so flour types with high-fat contents are desirable for utilize in low-moisture food products such as biscuits or cookies. The index of TPC for WF $(8.21 \mathrm{mg}$ $\mathrm{GAE} / 100 \mathrm{~g}$ ) was much lower compared to $\mathrm{AF}$ (49.8 mg GAE/ $100 \mathrm{~g}$ ). Adom et al. (2003) reported that TPC for various wheat varieties was within the limit of 710-860 $\mu \mathrm{mol}$ gallic acid/g. Finally, the AF had a higher caloric value (402.7 $\pm 18 \mathrm{kcal} / 100 \mathrm{~g} \mathrm{dm}$ ) probably as a result of its higher fat content which is in close agreement with Silva et al. (2016). Therefore, due to its higher nutritional value and TPC, AF was added to WF to upgrade the bread functional properties.

\subsection{Rheology of the dough}

A farinograph analysis was performed to evaluate the effect of different $\mathrm{AF}$ percentages substituted for $\mathrm{WF}$ on the mixing and develops properties of the dough and is presented in Table 1. Water absorption significantly $(\mathrm{p}<0.05)$ decreased as $\mathrm{AF}$ substituted WF and the control had the maximum water absorption. The ability to water absorb, applied by farinograph, depends on the protein content and damaged starch, as well as on the power of gluten to entrap water and lead to be positively related to bread yield. Thus, substitution of WF with AF suggested a decrease in the gluten content and subsequent water absorption of the sample.

The dough stability and development time significantly increased $(\mathrm{P}<0.05)$, while a significant decrease $(\mathrm{P}<0.05)$ in degree of softening was showed. Dough development time is defined as the time required to reach the maximum torque. Extending of dough stability to developing and mixing and confining drop of consistency (softening index), are both essential for dough spreading. The Degree of softening and dough stability time indicates the rate of breakdown and flour strength, with a lower degree of softening and a higher dough stability suggesting a stronger dough, according to Alaunyte et al. (2012). The lower gluten content and the presence of tannins and hydrocolloids in AF led to retardation of water absorption, extending the dough development time. The interaction of the acorn fibre and wheat gluten could improve the gluten network during mixing and cause such a decrease in degree of softening. This is consistent with the result reported by $\mathrm{Hu}$ et al. (2017), who reported that the dough with a longer stability time always exhibited a lower weakening index.

The dough properties, including extensibility and resistance to extension at different fermentation times (45, 90 and $135 \mathrm{~min}$ ) with $10-50 \% \mathrm{AF}$ substitution were determined by extensograph. According to the results presented in Table 3, in each of the samples with an increasing $\mathrm{AF}$ substitution level, the resistance to deformation and the extensibility of the dough significantly $(p<0.05)$ increased and decreased, respectively. It may result with the increment time of fermentation, the dough lost its resistance to long-term proofing; thus, the proofing time should be decreased.

Since the properties of the flour gluten is directly related to the results of extensograph, the increased dough resistance to deformation at 0$30 \%$ substitution can be explained by the interaction between the fibre content of AF and gluten network. The reduction in the samples' gluten content (40-50\% substitution) caused a decrease in the dough's resistance to deformation. Decreasing the extensibility of the dough due to the formation of capable gluten and fibre network led to its higher firmness and speeds up tearing, according to Rosell et al. (2001).

A correlation seems to exist between the farinograph and extensograph indices. Comparing the results of the dough properties with the water absorption decrease proportional to the level of acorn flour added, it is revealed that the interactions between the gluten matrix of the dough and added the acorn have been so strong that could increase the consistency of the dough structure. 
Biotechnological properties of Acorn toast | 327

Table 2: Proximate composition of wheat and acorn flours

\begin{tabular}{lcc}
\hline Parameters & Acorn flour & Wheat flour \\
\hline Moisture (\%) & 4.12 & 13.12 \\
Fat (\%) & 6.49 & 2.38 \\
Ash (\%) & 2.19 & 0.76 \\
Protein (\%) & 11.13 & 4.21 \\
Fibre (\%) & 3.11 & 0.42 \\
Energy (Kcal) & 402.7 & 320.8 \\
Total phenolic content (mg GAE/100g) & 49.8 & 8.22 \\
\hline
\end{tabular}

Reported values are the mean of at least 3 replicates

Table 3: Total phenolic content, peroxide value and staling properties of the breads containing 0-30\% acorn flour. Different letters show significant differences at a significance level of $5 \%$.

\begin{tabular}{|c|c|c|c|c|c|c|c|c|}
\hline \multirow{2}{*}{$\begin{array}{c}\text { Acorn flour } \\
\text { level }(\%)\end{array}$} & \multicolumn{3}{|c|}{ Enthalpy (j/g) } & \multicolumn{3}{|c|}{ Firmness $(\mathrm{N})$} & \multirow{2}{*}{$\begin{array}{l}\text { Total phenolic content } \\
\qquad(\mathrm{mg} \text { GAE } / \mathrm{g})\end{array}$} & \multirow{2}{*}{$\begin{array}{l}\text { Peroxide value } \\
\left(\text { meq } \mathrm{O}_{2} / \mathrm{kg}\right)\end{array}$} \\
\hline & After $24 \mathrm{~h}$ & After $48 \mathrm{~h}$ & After $72 \mathrm{~h}$ & After $24 \mathrm{~h}$ & After $48 \mathrm{~h}$ & After $72 \mathrm{~h}$ & & \\
\hline 0 & $1.23 \pm 0.01^{a}$ & $2.41 \pm 0.05^{b}$ & $3.57 \pm 0.33^{a}$ & $102 \pm 2.33^{c}$ & $106 \pm 3.3^{c}$ & $105 \pm 2.51^{d}$ & $0.52 \pm 0.04^{d}$ & $5.33 \pm 0.61^{a}$ \\
\hline 10 & $0.88 \pm 0.001^{b}$ & $2.33 \pm 0.03^{b}$ & $3.17 \pm 0.05^{b}$ & $104 \pm 1.12^{c}$ & $112 \pm 2.2^{c}$ & $129 \pm 3.4^{c}$ & $4.87 \pm 0.63^{c}$ & $2.17 \pm 0.052^{b}$ \\
\hline 20 & $0.54 \pm 0.003^{c}$ & $2.37 \pm 0.11^{b}$ & $3.22 \pm 0.05^{b}$ & $153 \pm 3.01^{b}$ & $155 \pm 1.88^{b}$ & $178 \pm 3.7^{b}$ & $6.32 \pm 0.88^{b}$ & $1.03 \pm 0.31^{c}$ \\
\hline 30 & $0.95 \pm 0.01^{a b}$ & $2.98 \pm 0.2^{a}$ & $3.64 \pm 0.08^{a}$ & $194 \pm 0.25^{a}$ & $199 \pm 3.63^{a}$ & $231 \pm 2.55^{a}$ & $9.44 \pm 0.67^{a}$ & $0.36 \pm 0.05^{b}$ \\
\hline
\end{tabular}

\subsection{Bread retrogradation}

It has been reported that staling caused reorganization of the gelatinized starch in an ordered crystalline structure known as retrogradation as described by AACC (2000). This re-crystallization leads to staling of cereals and food products. Katina et al. (2006) reported that one way to measure bread staling is measurement of the heat required to melt crystallized starch. The obtained enthalpy was the meaningful parameter for detecting significant differences lead to staling in the bread firmness.

The enthalpy of the control, 10, 20 and $30 \%$ acorn bread after 24,48 and $72 \mathrm{~h}$ of storage are shown in Table 3 . The panellists gave the lowest score of overall acceptability to the 40 and $50 \%$ acorn bread samples; they were therefore discarded and were not subjected to the staling test.

For fresh bread (on the day of baking), a decrease in the enthalpy in comparison to the control by addition of AF at 10 and $20 \%$ was observed, although an increase was showed at 30\% substitution. The exact levels of this addition were not statistically significant in the reduction of the melting enthalpy in comparison with the control. Differences were observed between the enthalpies of the samples with different levels of AF which were proportional to the replacement levels on the second and third day of storage.

The firmness values of the bread in the course of storage are presented in Table 3. In most cases, bread firmness increased significantly over the storage period. However, the addition of AF changed the degree of these modifications. On the day of storage, the loaves with 20 and 30 $\%$ AF were comparably as firm as the control. Thus, it implied that after 24, 48 and $72 \mathrm{~h}$ of baking, staling of the sample with $20 \%$ AF was lower than of the control and this sample went staler compared to the control. The reduction in the recrystallization enthalpy of amylopectin and the rise in firmness could be caused by three factors. I) Partial substitution of starch with AF caused a reduction in the total amount of amylopectin in the system, II) amylopectin could interact with $\mathrm{AF}$ and retard its re-crystallization and III) Amylose chains' content could bind with fibres and hydrocolloids and inhibit them from

IJFS | October 2021 | Volume $10 \mid$ pages 322-333 
linking to each other. It seems that the low fat, fibre and hydrocolloid contents of the sample with $20 \%$ AF did not restrict staling, because this amount of fat and hydrocolloids was too little to cover the flour particles and consequently staling occurred (Gray \& Bemiller, 2003). Therefore, it would control water mobility and preserve starch from going stale and the texture from becoming hard. It should be mentioned that staling is a complex process that includes re-crystallization of amylopectin only as one of many factors.

\subsection{Phenolic analysis}

Total phenolic content (TPC) and peroxide value (PV) of the bread samples containing various percentages of AF are presented in Table 3. The results suggested that by increasing acorn levels, TPC of the breads significantly increased. Some of the literature reports that tea had polyphenols which, have a noticeable preventable impact on the rice starch retrogradation (Wu et al., 2009). In this research we did not show any significant correlation between TPC of the bread samples and the enthalpy of retrogradation.

Acorn bread samples with peroxide values (PV) of $0-50 \%$ were used to evaluate the impact of the temperature of baking on the acorn oil, as well as on the shelf life of the breads (Table 3). As the replacement of the level of AF for WF increased, $\mathrm{PV}$ was found to decrease. This indicates that the increment of antioxidants and phenolic compounds decreased the oxidation of the bread compounds during baking and consequently PV decreased.

\subsection{Bread properties}

The physical properties of the composite bread including various levels of AF substitution are shown in Table 4. It was found that with increasing concentration of AF at the same water content, the volume of the samples decreased $24.39 \%$. Fibres can modify bread loaf volume and the firmness of the loaf. As a rule, the incorporation of fibres in bread reduces loaf volume and increases firmness (Table 3), but the extent of modification depends on the fibre source (Elleuch et al., 2011). Moreover, Kurek and Wyr- wisz (2015) revealed that a reduction in the loaf volume of the breads obtained, was the main problem of the addition of dietary fibre to bakery products.

It was found that as the substitution of AF in the mixture increased, the breads became darker as evidenced by the lower $\mathrm{L}^{*}$ index of the mixture in comparison to that of the control. Pasqualone et al. (2019) remarked that, the addition of acorn flour caused darkening in biscuits. Browning was due to the phenolic fraction of flour, which is known to easily undergo oxidation by polyphenoloxidase (Pasqualone et al., 2014; Taranto et al., 2012).

The lowest index (63.32) L* was for $50 \% \mathrm{AF}$ bread and the highest one (91.62) belonged to the control sample as shown in Table 4. An increase in $a^{*}$ and $b^{*}$ values of the bread may be due to the inherent dark colour of the acorn meal. In the case of $a^{*}$, the addition of AF resulted in its change from negative to positive values, signifying the supremacy of red over green in the bread colour. In all cases, the value of $b^{*}$ was positive, which corresponds to that yellow was more intensive than blue both in the control and AF-containing breads. Replacement of WF with AF caused an increase in crumb yellowness. The results were consistent with a previous study by Skendi et al. (2018).

The porosity of the breads which, was characterized by digital image analysis, is depicted in Figure 1. The sample with $30 \%$ substitution of AF was characterized as the most porous sample. Substitution of $40-50 \%$ AF caused a decrease in porosity to values comparable with or higher than those observed for the control. The reduction in porosity is probably due to a dilution of gluten and the interruption of its structure by the increased AF content, providing impairment in gas retention. The results are consistent with the study reported by Korus et al. (2015).

Sensory evaluation is the key procedure to assess the quality of food and requires a small sample size and less time. The descriptive evaluation of the sensory results of the breads made from WF and various concentrations of AF are presented in Figure 2.

The $40 \%$ substitution of AF had a remarkable impact on the appearance of the bread. Further addition of AF up to $50 \%$ caused a decrease in 


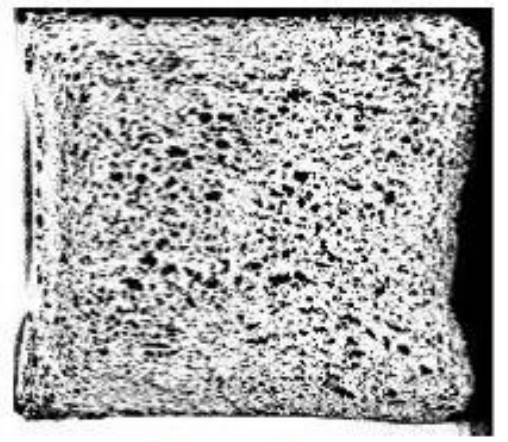

Control

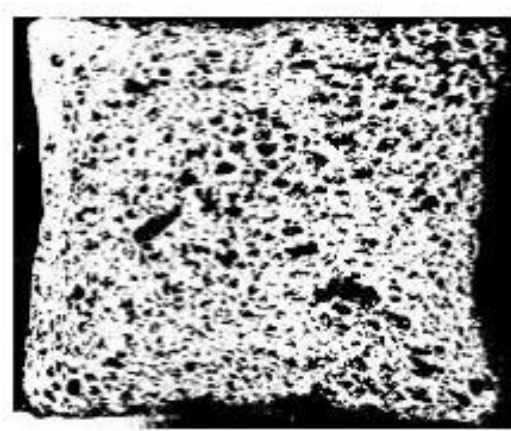

B

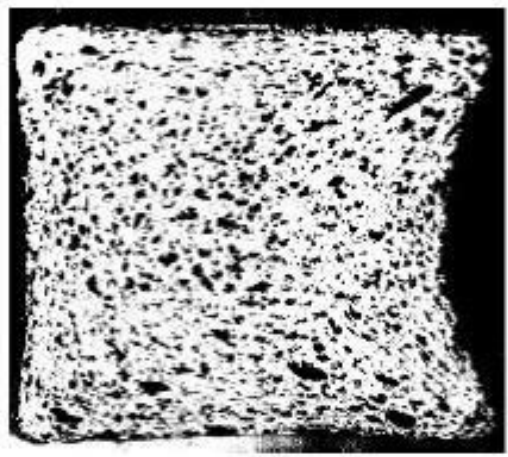

D

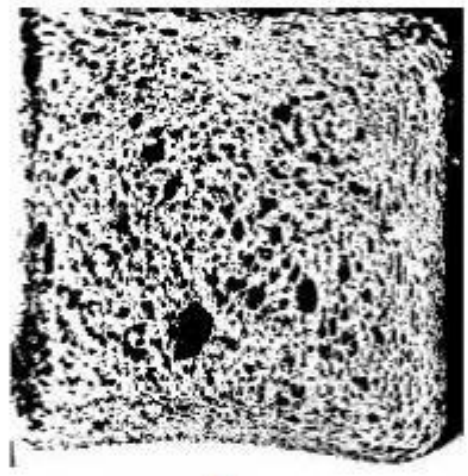

A

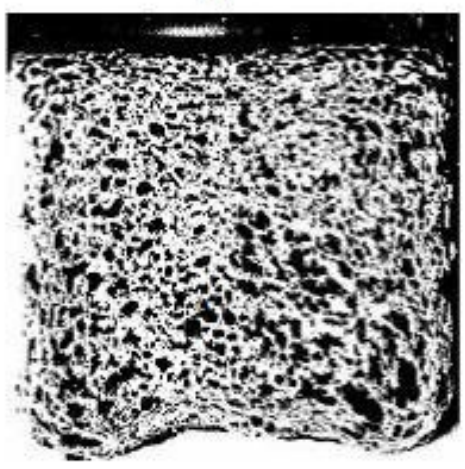

C

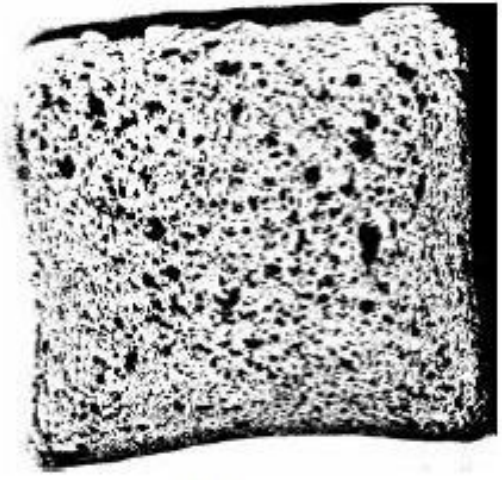

E

Figure 1: Effect of Acorn Flour addition on the internal structure of toast bread. Control: 100\% Wheat bread; A) mixture of $90 \%$ refined Wheat Flour (70\% extraction rate) and $10 \%$ Acorn Four; B) mixture of $80 \%$ refined Wheat Flour (70\% extraction rate) and 20\% Acorn Flour; C) mixture of $70 \%$ refined Wheat Flour (70\% extraction rate) and 30\% Acorn Flour; D) mixture of $60 \%$ refined Wheat Flour $(70 \%$ extraction rate) and $40 \%$ Acorn Flour; E) mixture of $50 \%$ refined Wheat Flour (70\% extraction rate) and $50 \%$ Acorn Flour. 
Table 4: The results of the proximate analysis and physical properties of the bread samples

\begin{tabular}{lcccc}
\hline Acorn flour level (\%) & Bread volume $\left(\mathrm{cm}^{3}\right)$ & L*value $^{*}$ & a*value & b*value \\
\hline 0 & $318.67 \pm 3.22^{a}$ & $91.62 \pm 1.5^{a}$ & $-1.21 \pm 0.05^{d}$ & $12.7 \pm 0.9^{b}$ \\
10 & $279.32 \pm 1.17^{b c}$ & $87.60 \pm 2.3^{b}$ & $4.31 \pm 0.9^{c}$ & $17.7 \pm 0.85^{a}$ \\
20 & $277.21 \pm 2.8^{c}$ & $73.33 \pm 2.03^{c}$ & $6.85 \pm 1.1^{b}$ & $17.2 \pm 0.36^{a}$ \\
30 & $280.50 \pm 1.01^{b}$ & $70.91 \pm 2.03^{c d}$ & $7.12 \pm 0.8^{a b}$ & $17.2 \pm 0.74^{a}$ \\
40 & $263.46 \pm 1.6^{d}$ & $67.42 \pm 1.1^{d}$ & $7.75 \pm 1.32^{a}$ & $17.1 \pm 1.1^{a}$ \\
50 & $240.91 \pm 2.4^{e}$ & $63.32 \pm 1.3^{e}$ & $7.6 \pm 0.5^{a b}$ & $16.5 \pm 1.02^{a}$ \\
\hline
\end{tabular}

Values are mean \pm standard deviation $(n=3)$. Mean values in the same row sharing different superscripts were significantly different $(\mathrm{P}<0.05)$.

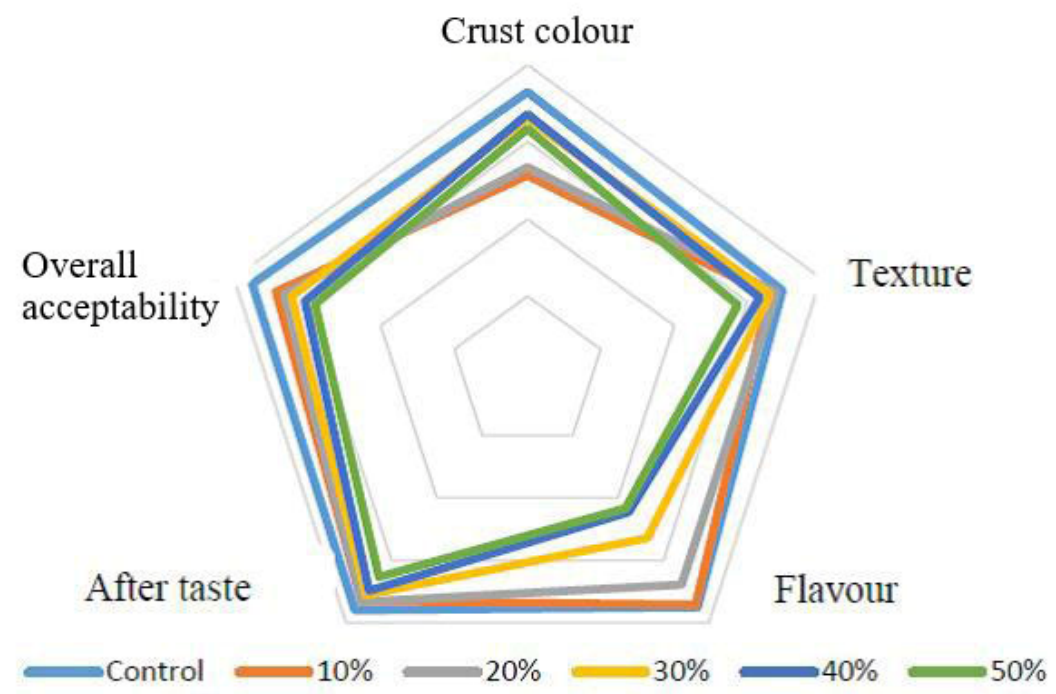

Figure 2: Results of the sensory evaluation of the control and acorn bread samples.

the score of this attribute. Flavour and texture were also more acceptable for $0-30 \%$ substitution than other samples. The highest overall acceptability score (7.43) was given to $30 \%$ AF bread and in higher levels of replacement, acceptability scores decreased. The bread with $50 \%$ AF substitution had the minimum acceptable taste. Therefore, the addition of AF (up to 30\%) had a clearly positive impact on the overall acceptance and the sensory attributes of the toast bread.

\section{Conclusion}

This research was undertaken to see the potential of acorn flour addition on the physicochemical properties of Iranian toast bread, and has achieved new findings. Acorn flour expressed a higher fibre content, protein, fat compared than wheat flour. Adding acorn flour had considerable changes in rheological properties. The degree of softening, water absorption and dough extensibility decreased, while dough stability, development times and resistance to extension increased. The brightness of the bread crust decreased significantly with the increased acorn flour level and 
the toast became darker with the acorn flour enrichment, compared to the control. Acorn was found to be higher in antioxidant capability as evidenced by its higher phenolic content and lower peroxide value compared to the control toast. According to the panellist's score in the sensory evaluation and considering the results obtained in this experiment, Iranian toast enriched with $30 \%$ acorn flour was suggested as an acceptable and beneficial food.

\section{Acknowledgements}

The authors acknowledged the staff of the laboratories of Yasouj University of medical sciences.

\section{References}

AACC. (2000). Approved Methods of the American Association of Cereal Chemists. Methods, 54, 21. St. Paul, MN, U.S.A.

Adom, K. K., Sorrells, M. E. \& Liu, R. H. (2003). Phytochemical profiles and antioxidant activity of wheat varieties. Journal of Agricultural and Food Chemistry, 51(26), 7825-7834. https:// doi . org/10.1021/jf0304041

Alaunyte, I., Stojceska, V., Plunkett, A., Ainsworth, P. \& Derbyshire, E. (2012). Improving the quality of nutrient-rich teff (eragrostis tef) breads by combination of enzymes in straight dough and sourdough breadmaking. Journal of Cereal Science, 55(1), 22-30. https://doi. org/10.1016/j.jcs.2011.09.005

AOCS. (2003). Official methods and recommended practices of the american oil chemists' society (A. press, Ed.).

Atwater, W. O. (1902). Experiments on the metabolism of matter and energy in the human body, 1898-1900. US Government Printing Office.

Elleuch, M., Bedigian, D., Roiseux, O., Besbes, S., Blecker, C. \& Attia, H. (2011). Dietary fibre and fibre-rich by-products of food processing: Characterisation, technological functionality and commercial applications: A review. Food Chemistry,
124(2), 411-421. https:// doi.org / 10 .

1016/j.foodchem.2010.06.077

Ferrari, C. K. B. \& Torres, E. A. F. S. (2003). Biochemical pharmacology of functional foods and prevention of chronic diseases of aging. Biomedicine \&3 Pharmacotherapy, 57(5-6), 251-260. https://doi.org/ 10.1016/S0753-3322(03)00032-5

Ghaderi-Ghahfarrokhi, M., Sadeghi-Mahoonak, A. R., Alami, M. \& Khanegah, M. A. (2017). Effect of processing treatments on polyphenol removal from kernel of two iranian acorns varieties. International Food Research Journal, 24(1), 8693.

Gray, J. A. \& Bemiller, J. N. (2003). Bread staling: Molecular basis and control. Comprehensive Reviews in Food science and food safety, 2(1), 1-21.

Hadnadev, T. D., Torbica, A. \& Hadnadev, M. Rheological properties of wheat flour substitutes/alternative crops assessed by mixolab (G. Saravacos, P. Taoukis, M. Krokida, V. Karathanos, H. Lazarides, N. Stoforos, C. Tzia \& S. Yanniotis, Eds.) [11th International Congress on Engineering and Food (ICEF), Athens, GREECE, MAY 22-26, 2011]. In: In 11th international congress on engineering and food (icef11) (G. Saravacos, P. Taoukis, M. Krokida, V. Karathanos, H. Lazarides, N. Stoforos, C. Tzia \& S. Yanniotis, Eds.). Ed. by Saravacos, G., Taoukis, P., Krokida, M., Karathanos, V., Lazarides, H., Stoforos, N., Tzia, C. \& Yanniotis, S. 1. Procedia Food Science. 11th International Congress on Engineering and Food (ICEF), Athens, GREECE, MAY 22-26, 2011. 2011, 328334. https://doi.org/10.1016/j.profoo. 2011.09.051.

Hartzfeld, P. W., Forkner, R., Hunter, M. D. \& Hagerman, A. E. (2002). Determination of hydrolyzable tannins (gallotannins and ellagitannins) after reaction with potassium iodate. Journal of $\mathrm{Ag}$ ricultural and Food Chemistry, 50(7), 1785-1790. https: / / doi.org/10.1021/ jf0111155 
Hu, Y., Wang, L. \& Li, Z. (2017). Modification of protein structure and dough rheological properties of wheat flour through superheated steam treatment. Journal of Cereal Science, 76, 222-228. https://doi. org/10.1016/j.jcs.2017.06.013

Katina, K., Salmenkallio-Marttila, M., Partanen, R., Forssell, P. \& Autio, K. (2006). Effects of sourdough and enzymes on staling of high-fibre wheat bread. $L W T$ - Food Science and Technology, 39(5), 479-491. https: / / doi .org / 10.1016/j . lwt.2005.03.013

Korus, J., Witczak, M., Ziobro, R. \& Juszczak, L. (2015). The influence of acorn flour on rheological properties of gluten-free dough and physical characteristics of the bread. European Food Research and Technology, 240(6), 1135-1143. https:// doi.org/10.1007/s00217-015-2417-y

Kurek, M. \& Wyrwisz, J. (2015). The application of dietary fiber in bread products. Journal of Food Processing and Technology, 6(5), 447-450.

Lin, L.-Y., Liu, H.-M., Yu, Y.-W., Lin, S.-D. \& Mau, J.-L. (2009). Quality and antioxidant property of buckwheat enhanced wheat bread. Food Chemistry, 112(4), 987-991. https : / / doi .org / 10.1016/j. foodchem.2008.07.022

Marpalle, P., Sonawane, S. K. \& Arya, S. S. (2014). Effect of flaxseed flour addition on physicochemical and sensory properties of functional bread. LWT - Food Science and Technology, 58(2), 614-619. https://doi.org/10.1016/j.lwt.2014.04. 003

Mohammadzadeh, A., Samadi-Maybodi, A. \& Khodadoust, S. (2013). Determination of trace elements in soil, leaves and fruits of quercus brantii grown in southwestern iran by atomic spectroscopy. Spectrochimica Acta Part A-molecular and Biomolecular Spectroscopy, 113, 423426. https: / / doi .org / 10.1016/j. saa . 2013.04.080

Mousavi, B. \& Kadivar, M. (2018). Effect of brine solution as a wheat conditioner, on lipase, amylase, and lipoxygenase activities in flour and its corresponding dough rheological properties. Journal of Food Processing and Preservation, 42(6). https: / / doi.org/10.1111/jfpp. 13631

Pasqualone, A., Delvecchio, L. N., Mangini, G., Taranto, F. \& Blanco, A. (2014). Variability of total soluble phenolic compounds and antioxidant activity in a collection of tetraploid wheat. Agricultural and Food Science, 23(4), 307-316. https:// doi. org/10.23986/afsci.47985

Pasqualone, A., Makhlouf, F. Z., Barkat, M., Difonzo, G., Summo, C., Squeo, G. \& Caponio, F. (2019). Effect of acorn flour on the physico-chemical and sensory properties of biscuits. Heliyon, 5(8). https: //doi.org/10.1016/j.heliyon.2019.e02242

Perez-Jimenez, J. \& Saura-Calixto, F. (2005). Literature data may underestimate the actual antioxidant capacity of cereals. Journal of Agricultural and Food Chemistry, 53(12), 5036-5040. https:// doi. org/10.1021/jf050049u

Polimac, M. \& Komlenić, D. K. Acorn flournaturally gluten free. In: Proceedings of the 8th international congress flourbread'15, 10th croatian congress of cereal technologists, opatija, croatia, october 29-30, 2015. Faculty of Food Technology Osijek, Josip Juraj Strossmayer University. 2016, 177-181.

Primo-Martin, C., van Nieuwenhuijzen, N. H., Hamer, R. J. \& van Vliet, T. (2007). Crystallinity changes in wheat starch during the bread-making process: Starch crystallinity in the bread crust. Journal of Cereal Science, 45(2), 219-226. https: //doi.org/10.1016/j.jcs.2006.08.009

Rakić, S., Maletić, R. O., Perunović, M. N. \& Svrzić, G. (2004). Influence of thermal treatment on tannin content and antioxidation effect of oak acorn quercus cerris extract. Journal of Agricultural Sciences, Belgrade, 49(1), 97-107.

Rosell, C. M., Rojas, J. A. \& de Barber, C. B. (2001). Influence of hydrocolloids on dough rheology and bread quality. Food Hydrocolloids, 15(1), 75-81. https://doi. org/10.1016/S0268-005X(00)00054-0 
Biotechnological properties of Acorn toast |333

Sabrin, M. D. (2009). Characterization of acorn meal (Doctoral dissertation). uga.

Silva, S., Costa, E. M., Borges, A., Carvalho, A. P., Monteiro, M. J. \& Pintado, M. M. E. (2016). Nutritional characterization of acorn flour (a traditional component of the mediterranean gastronomical folklore). Journal of Food Measurement and Characterization, 10(3), 584588. https://doi.org/10.1007/s11694016-9340-1

Singleton, V. L., Orthofer, R. \& LamuelaRaventos, R. M. Analysis of total phenols and other oxidation substrates and antioxidants by means of folin-ciocalteu reagent (L. Packer, Ed.). In: In Oxidants and antioxidants, pt a (L. Packer, Ed.). Ed. by Packer, L. Vol. 299. Methods in Enzymology. 1999, pp. 152-178. ISBN: 0$12-182200-1$.

Skendi, A., Mouselemidou, P., Papageorgiou, M. \& Papastergiadis, E. (2018). Effect of acorn meal-water combinations on technological properties and fine structure of gluten-free bread. Food Chemistry, 253, 119-126. https:// doi.org/10.1016/j . foodchem.2018.01.144

Taranto, F., Delvecchio, L. N., Mangini, G., Del Faro, L., Blanco, A. \& Pasqualone, A. (2012). Molecular and physico-chemical evaluation of enzymatic browning of whole meal and dough in a collection of tetraploid wheats. Journal of Cereal Science, 55(3), 405-414. https://doi.org/ 10.1016/j.jcs.2012.02.005

Wu, Y., Chen, Z., Li, X. \& Li, M. (2009). Effect of tea polyphenols on the retrogradation of rice starch. Food Research International, 42(2), 221-225. https:// doi. org/10.1016/j.foodres.2008.11.001 